\title{
Nickel-Catalyzed Coupling of Alkyl Halides and Alkyl Grignard Reagents
}

Synthesis

Key words

alkyl halides

cross-coupling

Grignard reagents

nickel complexes

SYNFACTinh<smiles>CCCCCCCC(=O)OCC</smiles>

$85 \% ; \mathrm{X}=\mathrm{Br}$

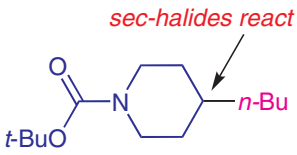

$86 \% ; X=1$

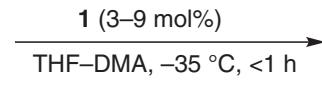

$R^{1} \stackrel{i}{-} R^{2}$

in THF

dary $R^{2}=$ primary Alk

$\mathrm{DMA}=N, N$-dimethylacetamide

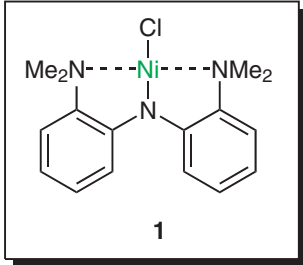

Examples (with 3 mol\% of 1 ):
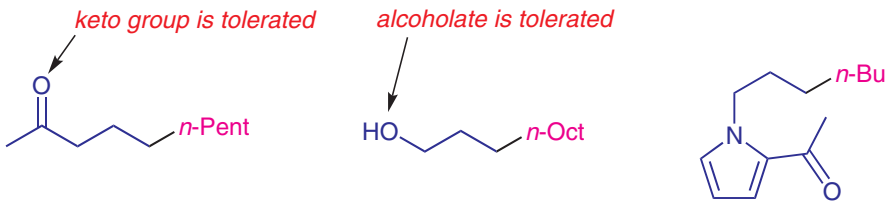

$60 \% ; \mathrm{X}=1$

$60 \% ; \mathrm{X}=\mathrm{Br}$, OctMgCl (2 equiv)

$93 \% ; \mathrm{X}=1$

$9 \mathrm{~mol} \%$ of 1
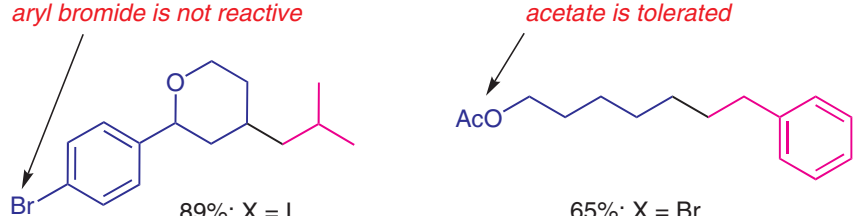

$65 \% ; \mathrm{X}=\mathrm{Br}$

Significance: Grignard reagents are desirable nucleophiles in coupling reactions, since they are inexpensive and easy to prepare. The use of a pincer nickel complex (1) enables their highly efficient $\mathrm{sp}^{3}-\mathrm{sp}^{3}$ cross-coupling with alkyl bromides and iodides. The reaction proceeds at low temperatures, so that even highly reactive functionalities like ketones are tolerated.
Comment: Alkyl bromides and alkyl iodides react at similar rates, while alkyl chlorides are inert. Interestingly, aryl bromides do not participate in the coupling under these conditions. N,N-Dimethylacetamide (its mixture with THF) is the solvent of choice, NMP and other solvents give lower yields. Nickel(IV)-bis(alkyl) intermediates are tentative intermediates in this reaction. 